\title{
BIOLOGIA REPRODUTIVA DE Clidemia hirta (L.) D. DON (MELASTOMATACEAE).
}

\section{Sidney Alberto N. FERREIRA ${ }^{1}$, Isaac COHEN Antonio ${ }^{2}$, Mauro Roberto A. JANSEN ${ }^{1}$}

RESUMO - Este trabalho foi desenvolvido com a finalidade de apresentar algumas considerações sobre a biologia reprodutiva de Clidemia hirla. Conclui-se que: 1) A ântese tem início em torno das 18:00 h e termina por volta das $09: 00$ h do dia seguinte; 2) Esta é uma espécie preferencialmente alógama, porém não apresenta auto-incompatibilidade genética; 3) A polinização parece depender de agentes polinizadores, principalmente abelhas das famílias A pidae (Bombus, Melipona, Euglossa, Trigona) e Halictidae.

Palavras-chave: Clidemia hirta, biologia reprodutiva, alogamia, abelhas.

Reprodutive biology of Clidemia hirta (L.) D. Don (Melastomataceae).

ABSTRACT - Some aspects of reprodutive hiology of Clidemia hirta were observed. It was noticed: a) The anthesis begins at about 6:00 PM and ends at about 9:00 AM of the next day; b) Clidemia hirta is preferentially allogamous, but shows no genetic autoincompatibility; c) Clidemia hirta is pollinated by bees of Apidae (Bombus, Melipona, Euglossa, Trigena) and Halictidae families.

Key-words: Clidemia hirta, reprodutive biology, allogamy, hees.

\section{INTRODUÇÃO}

\section{Clidemia hirta é uma planta que} ocorre em áreas parcialmente sombreadas como margem de bosques, estradas e plantios (dendê, guaraná, seringa, etc.), em ambientes quentes e úmidos. Sua distribuição geográfica dáse por toda a América tropical úmida e parte dos trópicos do velho mundo (WURDACK, 1973). É considerada uma planta colonizadora, por outro lado, quando ocorre em áreas cultivadass é tida como uma invasora, que concorre por água e nutrientes do solo com a cultura, além de hospedar patógenos direta e indiretamente, como fitófagos mastigadores e trips que são vetores de viroses. Pode ter importância para a meliponicultura devido ser visitada por abelhas da espécie Melipona fulva .

Clidemia hirta é um arbusto que cresce até cerca de $2,0 \mathrm{~m}$ de altura (WURDACK, 1973). Possui intensa pilosidade no caule herbáceo, pecíolos e limbo foliar (página inferior e superior). As folhas são simples, opostas, cordiformes, com borda serrilhada e curvinérvea. Inflorescências terminais, às vezes entre a bifurcação do caule; do tipo dicásio, com flores andróginas, de pedicelo piloso, com pequenas bractéolas; cíclicas; actinomorfas, heteroclamídeas; sépalas soldadas, apresentando pilosidade; pétalas levemente soldadas na base, glabras, brancas, obovadas, pentâmeras, raras vezes hexîmeras; epígenas; dialiostêmones, com 10 estames (flor pentâmera) e raramente 12 (flor hexâmera), dipostos em círculo, dobrados na flor fechada, distendendo-se horas após o início da ântese. As anteras são lanceoladas, com uma teca e duas câmaras que se comunicam na parte

INPA, Caixa Postal 478, 69(011-970, Manaus-AM:

EMBRAPA-CPAA, Caixal Postal 319, 69048-660, Manaus-AM. Brasil. 
apical, dando saída por um único poro. O gineceu é gamocarpelar; ovário com 5 lóculos, multiovulados; estilete apical, longistilo; estigma pouco vistoso. O fruto é uma baga de cor esverdeada e roxo escuro quando maduro, de formato globoso, com pelos no epicarpo formado pelo cálice persistente.

Neste trabalho, foram feitas algumas observações da biologia floral de Clidemia hirta que ocorre na Amazônia ocidental.

\section{MATERIAL E MÉTODOS}

O estudo foi desenvolvido na Estação Experimental de Silvicultura Tropical (EEST) do INPA, km 45 da BR 174, e no Campo Experimental da EMBRAPA-CPAA, $\mathrm{km} 30$ da rodovia AM-10, ambos no município de Manaus - AM, nos meses de abril e maio de 1991.

Para a observação da antese, na EEST-INPA, foram escolhidas, ao acaso, 5 plantas de $C$. hirta e, em cada uma destas, foram etiquetados 10 botões florais desenvolvidos, próximos de suas aberturas, os quais inicialmente foram examinados a cada intervalo de 2 horas. durante 24 horas.

Foi observado o comportamento dos insetos visitantes das flores de várials plantas circunvizinhas e, com a ajuda de rede entomológica, foi realizada a captura dos mesmos. Em seguida, procedeu-se o exame do pólen fresco encontrado no corpo dos insetos, comparando-se com o pólen fresco retirado das anteras das flores de C. hirta.

Aplicou-se o teste de Hidróxido de Amônio (SCOGIN et al 1977) para verificar as estruturas que refletem a radiação ultravioleta, com as flores em vários estágios, desde botão fechado até completamente aberta. De igual modo, efetuou-se o teste com Vermelho Neutro (VOGEL, 1962) para localizar osmóforos.

Os grãos de pólen sofreram desidratação em sílicagel por 24 horas, em seguida foram submetidos ao teste de "Cotton Blue" (BROWN, 1960 e DARLINGTON \& LA COUR. 1965) para constatação da presença de citoplasma.

Para o estudo do modo de reprodução de $C$. hirta, realizado no Campo Experimental da EMBRAPACPAA, foram feitas polinizações controladas, com os seguintes tratamentos: autopolinização, autogamia, geitonogamia, xenogamia, apomixia e polinização livre, realizadas no período de 07:00 s 09:00 horas, ocasião em que detectou-se que o pólen estava viável e o estigma receptível. As polinizações foram feitas com auxílio de 2 pinçás de penta fina, que foram sempre flambadas, ao término de cada polinização. Para a polinizição livre, foram considerados os botões marcados para o estudo da ântese. No estudo de apomixia, foram emasculados 1.3 botões de 6 plantas, os quais foram em seguida isolados com sacos duplos de papel-manteiga. Para investigar a autopolinização, foram isoladas com o mesmo material 12 inflorescências em 12 plantas, num total de 69 botões observados. Para autogamia, geitonogamia e xenogamia, foram isolados, um dia antes da ântese, 30) botões, em 12 plantas, sendo 10 botões para cada tratamento. Após a 
abertura das flores, retirou-se o isolamento e efetuaram-se as polinizações, sendo em seguida novamente isoladas. A verificação da fecundação foi feita 72 horas depois, quando as flores não fecundadas caem e as que foram fecundadas desprendem as pétalas e o estilete.

\section{RESULTADOS E DISCUSSÃO}

Em Clidemia hirta, observou-se que o processo de ântese tem início entre às 18:00 e 22:00 $\mathrm{h}$, do dia que antecede a completa abertura das flores. Neste período, verificou-se que os botões florais apresentam-se bastante desenvolvidos, com um pequeno desenrolamento das pétalas, além de, algumas vezes, haver a emergência do estilete, expondo completamente o estigma ao ambiente. Baseando-se nestas características, às 22:00h, foi possível identificar praticamente todas as flores que iriam estar abertas no dia seguinte. As 04:00 $h$ verificou-se que as flores encontramse parcialmente abertas, alcançando a abertura total no intervalo de 06:00 as 09:00 horas. Por volta das 14:00 horas iniciava-se o processo de fechamento das pétalas. Em dias nublados e/ou chuvosos, nem sempre as flores completam sua abertura, passando do estágio semi-aberto para o de fechamento. Após completa abertura das pétalas, observou-se que os estames ainda se encontram dobrados ou encurvados, com as extremidades distais das anteras voltadas para a base dos estames, com o passar do tempo, distendem-se até ficarem completamente erguidos em volta do estilete. Observouse que as flores fecundadas perdem as pétalas, os estames e o estilete, no intervalo de 2 a 3 dias. Por outro lado. quando não fecundadas, estas caem por inteiro entre 1 a 3 dias. Dos botões marcados para este estudo, $20 \%$ cairam antes da ântese.

No teste com hidróxido de amônio, verificou-se um escurecimento das bordas das pétalas, estígma e anteras, indicando que estas partes refletem raios ultravioleta e que podem funcionar como elemento de atração e guia de alimento para os insetos que visitam as flores de $C$. hirta.

No teste com vermelho neutro, apenas o estigma se coloriu, revelando que este órgão possui células produtoras de perfume que pode servir de elemento de atração para os insetos visitantes, embora não seja: notado nenhum aroma marcante pelo olfato humano, na ocasião da antese.

Por meio do teste "Cotton Blue". verificou-se que a maioria dos grãos de pólen coloriram todo o citoplasma em azul, permanecendo viáveis, após 24 horas em sílica gel.

Na observação da floração de $C$. hirta, foram vistos vários insetos fitófagos, de diversals ordens, visitando a planta (Acrididae, Homopteras. Hemipteras), contudo, os insetos encontrados visitando as flores foram as abelhas (Tab.1) que parecem desenvolver um importante papel na reprodução de $C$. hirta e trips que provavelmente alimentam-se dos tecidos tenros das flores.

A abelha Bombus transversalis foi uma espécie encontrada todos os 
dias visitando as flores de $C$. hirta, no período de 10:00 as 12:00 horas. Antes de pousarem nas flores, estas abelhas faziam um vôo de reconhecimento. Seguido ao pouso, estes insetos faziam movimentos anteras das Melastomatáceas, causando danos, a fim de expor, ou tornar disponível, uma maior quantidade de pólen.

Melipona filva foi normalmente encontrada entre 10:00 e 11:00 horas.

Tabela 1. Abelhas visitantes de flores de Clidemia hirta, perto de Manaus-AM

\begin{tabular}{lcc}
\hline Familia & Tribo & Espécie \\
\hline Apidae & Bombini & Bombus transversalis \\
& Euglossini & Euglossa sp \\
& Meliponini & Melipona fulva \\
Halictidae & Trigonini & Trigona (Pissania) spp \\
\hline
\end{tabular}

circulares, passando a região do tórax/ abdomen no estígma. Foram encontrados dois tipos de pólen nas corbículas e região tórax/abdomen destas abelhas: um branco que se aparentava a olho nu com o pólen de C. hirta e um outro amarelo, de uma espécie desconhecida. Isto indica que C. hirta, pode concorrer na oferta de pólen com plantas cultivadas, pela visita de polinizadores.

Outras espécies visitantes muito freqüentes foram as trigonas. Estas, em geral, continham bastante pólen nas curbículas e nos pêlos da parte ventral do tórax. Quando sobre as flores, as mesmas caminhavam recolhendo pólen, encostando a região tórax/abdomen sobre o estigma. RENNER (1983) menciona 34 espécies brasileiras de Melastomatáceals que são visitadas por trigonas. Segundo a mesma autora, algumas destas abelhas chegam a romper as extremidades das
Quando sobre a flor, esta encurvavase e fazia movimentos vibratórios sobre a mesma. Este comportamento das abelhas, segundo MICHENER (1962), é comum em flores que possuem anteras com poro apical, em que o pólen não sai facilmente. $O$ mesmo autor, afirma que estas vibrações fazem com que os grãos de pólen saiam com força pelos poros apicais das anteras.

Quanto aos resultados das polinizações e apomixia realizadas em C. hirta (Tab.2), pode-se observar que não ocorreu autopolinização, afastando a possibilidade de haver cleistogamia e casmogamia. Também não houve formação de frutos no tratamento de apomixia, excluindo a hipótese de ocorrer agamospermia e paternocarpia. Nos tratamentos de autogamia, geitonogamia e xenogamia ocorreram fecundações com taxas de 80,100 e $100 \%$, respectivamente. 
Tabela 2. Resultados das polinizações e apomixia em Clidemia hirta na reģião de Manaus-AM

\begin{tabular}{lcccc}
\hline \multicolumn{1}{c}{ Tratamentos } & $\begin{array}{c}\text { No de } \\
\text { flores }\end{array}$ & $\begin{array}{c}\text { flores } \\
\text { fecundadas }\end{array}$ & $\begin{array}{c}\text { de } \\
\text { fecundação }\end{array}$ & $\begin{array}{c}\text { c/ 14 dias } \\
\text { após polinização }\end{array}$ \\
\hline Polinização livre & 48 & 9 & 19 & - \\
Autopolinização & 69 & 0 & 0 & 0 \\
Autogomia & 10 & 8 & 80 & 7 \\
Geitonogamia & 10 & 10 & 100 & 10 \\
Xenogamia & 10 & 10 & 100 & 10 \\
Apomixia & 13 & 0 & 0 & 0 \\
\hline
\end{tabular}

Deste modo, $C$. hirta parece não apresentar autoincompatibilidade genética, visto que houve altas taxas de fecundações nos autocruzamentos.

A polinização cruzadda parece ser o modo de reprodução mais freqüente em $C$. hirta. Isto pode ser explicado devido à morfologia das estruturas florais, com flores longistilo, que apresentam o estigma receptivel, horas antes dos estames se distenderem e possibilitarem a liberação do pólen.

\section{CONCLUSÕES}

Considerando as condições em que se desenvolveram as observações, podemos chegar às seguintes conclusões:

Em Clidemia hirta, a antese tem início em tomo das 18:00 h e termina por volta das 09:00 h do dia seguinte;

$$
\text { Esta é umal espécie }
$$

preferencialmente alógama c não apresenta problemas de auto-incompatibilidade genética;

A polinização é feita por insetos. principalmente abelhas das famnilias Apidae (Bombus, Melipona, Euglossa, Trigona) e Halictidae.

\section{AGRADECIMENTOS}

Agradecemos ao Prof. Dr. Pedro Ivo S. Braga (UFMG-MG) pela orientação no desenvolvimento deste trabalho e ao Dr. Francisco Aguilera Peralta (INPA-AM) pela identificação dos insetos.

\section{Bibliografia Citada}

BROWN, C. A. - 1960. Palyological tectsnizues. Louisiana, Baton Rouge.

DARLINGTON, C.D. \& LaCOUR, L.F. 1965. The handling of the chromosomes. London, George Album and Univers.

MICHENER. C. D. - 1962. An interesting method of pollen collecting by bees from flowers with tubular anthers. Rev: Biol. Trop.. 10(2): 167-175.

RENNER, S. - 1983. The widespread oceurrence of anther destruction by trigonat bees in Melastomataceac. Biotropica. 15(4): 251-256

SCOGIN, R.: YOUNG, D. A.: JONES, C.E. - 1977. Anthochlor pigments and pollination biology: II. The ultraviolet floral patterns of Coreopsis gigantea (Asteraceac). Bull. Tor: Bot. Club). $1(04(2): 1.55-1.59$. 
VOGEL, S. - 1962. Deftdrusen im dienste der Bestãaumbung. Akcal. Wiss. Abh. Math. - Naturwiss. Ki. 10: 599-763.

WURDACK, J. J. - 1973. Flora de Venesuela: Melastomataceae. Vol. III, 2a parte. Trad. T. de Agostini e J. Tello. Caracas, Instituto Botanico. p. 523-819. 